\title{
Levantamento de fauna silvestre no Terra Parque, municipio de Pirapozinho, estado de São Paulo
}

\author{
Bruna da Silva Luiz ${ }^{1}$, Maria Angélica Dalla Pria ${ }^{1}$, Rosa Maria Barilli Nogueira ${ }^{1}$, Glaucia Pradra Kanashiro ${ }^{1}$, \\ André Luis da Silva ${ }^{2}$, Ellyn Amanda Fonseca Martin ${ }^{1}$ \\ ${ }^{1}$ Universidade do Oeste Paulista - UNOESTE, Curso de Medicina Veterinária, Presidente Prudente, SP. ${ }^{2}$ Garden Ecotur \\ Presidente Prudente, SP. E-mail: ellyn@unoeste.br
}

\section{Resumo}

O levantamento de fauna silvestre se baseia em uma série de observações, a fim de catalogar espécimes em dada região. Objetivou avaliar a diversidade de fauna no Resort "Terra Parque", área com relevo colinoso e bioma de Mata Atlântica pertencente ao município de Pirapozinho - SP. A área local foi percorrida a pé, o monitoramento realizado foi utilizado 03 câmeras fotográficas automáticas com funcionamento ininterruptos, fixadas em árvores, registrando indivíduos em atividade diurna e noturna bem como observação direta para coleta dos dados de acordo com a existência de vestígios e pegadas. Os fragmentos do estudo foram divididos em 02 campanhas, cada uma com 05 dias consecutivos, na estação da primavera (outubro/2017), perfazendo 10 dias com 240 horas de dados amostrais. Análises obtidas do processo de monitoramento foram descritivas. Identificados mamíferos através de vestígios e pegadas: Chrysocyon brachyurus, Cerdocyon thous e Hydrochoerus hydrochaeris; Câmera AF1 resultou nas imagens de répteis - Salvator merianae e mamíferos - Dasypus novemcinctus e Nasua nasua; Câmera AF2 resultou em mamífero - Leopardus pardalis. As armadilhas fixadas em pontos estratégicos de áreas tiveram indícios de ocorrência de mamíferos em contrapartida para répteis são de difícil amostragem, por serem animais inconspícuos. Porém, foram capturados. Ao término do monitoramento foram confeccionadas placas informativas quanto à taxonomia. Conclui-se a importância do monitoramento para identificação dos espécimes para maximizar os esforços de conservação a nível local, tratando-se de um estabelecimento turístico.

Palavra-chave: armadilha; diversidade; espécies; fauna; silvestres.

Lifting of wild fauna in the Terra Parque, municipality of Pirapozinho, state of São Paulo

\begin{abstract}
The survey of wildlife is based on a series of observations in order to catalog specimens in a given region. The objective was to evaluate the diversity of fauna in the "Terra Parque" Resort, an area with hilly relief and an Atlantic Forest biome belonging to Pirapozinho - SP. The local area was walked on foot, the monitoring was performed using 03 automatic cameras with uninterrupted operation, fixed in trees, recording individuals in day and night activity as well as direct observation to collect the data according to the existence of traces and footprints. The fragments of the study were divided in 02 campaigns, each with 05 consecutive days, in the spring season (October / 2017), making 10 days with 240 hours of sample data. Analyzes obtained from the monitoring process were descriptive. Identified mammals through traces and footprints: Chrysocyon brachyurus, Cerdocyon thous and Hydrochoerus hydrochaeris; AF1 camera resulted in images of reptiles - Salvator merianae and mammals - Dasypus novemcinctus and Nasua nasua; Camera AF2 resulted in mammal - Leopardus pardalis. The traps fixed at strategic points of areas had indications of occurrence of mammals in counterpart to reptiles are difficult to sample because they are inconspicuous animals. However, they were captured. At the end of the monitoring, information boards were elaborated regarding the taxonomy. The importance of monitoring for identification of specimens to maximize conservation efforts at the local level, as a tourist establishment, is concluded.
\end{abstract}

Keyword: trap; diversity; species; fauna; wid. 


\section{Introdução}

No que diz respeito aos animais de vida livre, a situação é preocupante, principalmente devido às necessidades de uma população humana crescente em morar e se alimentar, regidas pela estimulação de uma sociedade de consumo. Tem-se evidenciado, gradativamente, que a fauna silvestre desempenha um papel muito mais relevante e essencial para a sociedade com a contribuição fundamental desses seres para o bem-estar humano (DIRZO et al., 2014).

O Brasil é considerado megadiverso por possuir um patrimônio genético incomparável nos seus mais ricos ecossistemas. A fauna silvestre é composta por $10 \%$ (658) dos mamíferos (mastofauna), 18\% (1.800) das aves (avifauna), 46\% (680) dos répteis e 13\% (800) dos anfíbios (herpetofauna), sendo os dois primeiros grupos bio-indicadores mais eficientes nos monitoramentos. Além disso, se encontra a maior cobertura de floresta tropical do mundo (GREEN, 2004; BRANDON et al., 2005; BRASIL, 2014). Dentro de um determinado bioma, certas espécies são importantes para determinar a existência e/ou o tamanho de outras tantas populações de animais. Normalmente os predadores de topo de cadeia, apresentam esse papel, uma vez que são responsáveis pelo controle das populações de outros animais (IUNC, 2015).

A fragmentação de habitats é hoje uma das maiores ameaças à diversidade biológica tanto pela redução dos ambientes naturais como pela divisão dos habitats remanescentes em fragmentos menores e isolados. O manejo de fauna pode ser considerado como a interferência direta ou indireta do homem sobre indivíduos ou populações de uma ou várias espécies, visando à manutenção ou a modificação do seu estado atual em um determinado ambiente (LEAL, 2001; POTTS et al., 2010). A rápida alteração climática afeta os ecossistemas e as espécies. Incapazes de adaptar-se às novas condições têm suas populações reduzidas ou mesmo se extinguem o que implica na perda de biodiversidade (SHAH, 2012). A fauna silvestre brasileira, o número de espécies ameaçadas de extinção no Brasil aumentou consideravelmente, de 218 espécies em 1989 para 1.173 em 2014 (BRASIL, 2014).

Os processos de monitoramento são necessários a fim de maximizar os esforços de conservação a nível local, especialmente em regiões onde existem poucos dados sobre diversidade, abundância e distribuição das espécies. As armadilhas fotográficas são adequadas para amostrar mamíferos de tamanho médio a grande, alguns pássaros terrestres e pequenos mamíferos, como os roedores (CULLEN JR, et al., 2006; BRASIL, 2014).

O objetivo do estudo foi avaliar a diversidade de fauna, utilizando câmera "trap" através das capturas de imagens fotográficas, catalogar as mesmas e realizar a elaboração de placas informativas quanto à taxonomia de cada espécie a nível local. Sendo assim, a distribuição das armadilhas em uma determinada área de estudo deve ser muito bem planejada e delineada (O'CONNELL et al., 2011).

\section{Material e Métodos}

Local do experimento

O estudo foi realizado no "Terra Parque Eco Resort", localizado no município de Pirapozinho - SP, a uma latitude 2216'31" sul e a uma longitude 51930'00" oeste, estando a uma altitude de 487 metros. O bioma é Mata Atlântica, com área de 480,6941 e 0,00\% de desmatamento no período de 2008 - 2009. Localização hidrográfica Rio Santo Anastácio (ao norte/nordeste do município), Rio Pirapozinho (ao norte/noroeste do município), Córrego do Peru (ao sudeste/sul do município), Córrego da Onça (ao sudeste/sul do município) e Rio Paranapanema (ao sul/sudoeste do município, no Distrito de Itororó do Paranapanema). Apresenta um clima classificado como Tropical típico, com duas estações bem definidas: um inverno seco e um verão chuvoso. A temperatura média anual é de $23,5^{\circ} \mathrm{C}$.

\section{Material utilizado}

Foram utilizadas 03 câmeras fotográficas digitais automáticas, do modelo "HC300 Hunting Trail Câmera”. As câmeras utilizam armazenamento em cartões SD (Secure Digital) e pilhas alcalinas em seu funcionamento, desenvolvidas para, através de um sensor de infravermelho, realizaram o registro fotográfico de animais que passaram em frente ao dispositivo. Estes sensores possuem regulagem de sensibilidade e são ativados pelo calor corporal dos indivíduos e, portanto, também podem ser ativados pela incidência solar sobre o equipamento, sem que nenhum indivíduo seja registrado, gerando "fotos fantasmas". Para eliminar ou minimizar este problema, as câmeras foram instaladas em locais sombreados e, 
realizada a regulagem de sensibilidade do sensor de acordo com o local de instalação das câmeras.

Dados, colheita e processamento das amostras

Os dados da abundância de espécies de animais presentes nos fragmentos foram capturados através do uso de armadilha fotográfica ("câmera trapping"). Os fragmentos do estudo foram amostrados por um período de 05 dias consecutivo na estação da primavera (outubro/2017), abrangendo desta maneira o início da estação chuvosa na região, para a amostragem das armadilhas fotográficas. Totalizando 120 horas de amostragem. Seguindo com uma segunda campanha de 05 dias de esforço amostral com armadilhas fotográficas, que também totalizou 120 horas. Perfazendo 10 dias de levantamento de fauna, 240 horas. A área de estudo foi percorrida a pé, para a implantação dos equipamentos e coletas de dados do local. Os pontos de fixação das armadilhas foram determinados de acordo com, a existência de indícios ou de diversificação de pontos-de-vista, no qual foram identificados com rastos, vestígios e pegadas. As câmeras foram fixadas em árvores a uma altura em torno de $40 \mathrm{~cm}$ acima do solo e foram programadas para registrar indivíduos tanto em atividade diurna como noturna. Foram utilizadas, em frente às câmeras, iscas de cheiro, com a função de atrair animais para perto das câmeras, aumentando o número de registros de diferentes indivíduos e também com a função de maximizar o tempo em que os animais ficaram parados em frente ao dispositivo, possibilitando, assim, a obtenção de fotos com melhor qualidade para posterior identificação das espécies fotografadas.

Analise das amostras

Foram desconsideradas das análises as "fotos sequenciais", que são fotos de mesma espécie, em uma mesma câmera e com intervalo menor do que $1 \mathrm{~h}$ entre uma foto e outra. Este procedimento foi utilizado para diminuir as chances de que um mesmo indivíduo seja contabilizado mais de uma vez nas análises, evitando superestimar a abundância das espécies. As fotografias não sequenciais foram consideradas como registros independentes e contabilizadas.

As analises dos dados obtidos foram descritivas através do processo de monitoramento, capturas das imagens fotográficas pela câmera "trap", a fim de identificar as espécies da fauna existentes e presença de pegadas, onde há poucos dados sobre a diversidade, abundância e distribuição das espécies e, elaboração de placas informativas (taxonômicas).

\section{Resultados e Discussão}

O estudo se faz importante para o levantamento da diversidade de fauna local utilizando o método com armadilhas fotográficas e presença de pegadas.

O "Terra Parque - Eco Resort" apresenta uma localização hidrográfica (FIGURA 1). O parque está inserido na Unidade de Gerenciamento de Recursos Hídrico Pontal do Paranapanema (UGRHI 22), segundo Leite (1998).

O relevo encontrado no município onde está localizada a fazenda é da característica de relevo com colinas amplas e colinas médias (CPTI, 1999).

Conforme ainda no relato de Leite (1998), o clima da região é classificado no sistema de Köppen caracteriza-se pelo tipo CWA (mesotérmico, de inverno seco), caracterizado por temperaturas média anuais ligeiramente inferior a $22^{\circ} \mathrm{C}$, com chuvas típicas de clima tropical com precipitação que é marcadamente maior entre outubro a abril sendo o período com maior índice pluviométrico. Tal relato que condiz com o esperado durante as campanhas realizadas no local do levantamento de fauna e flora. 
Figura 1. Localização "Terra Parque - Eco Resort" no Municipio de Pirapozinho - SP e com a identificação da Unidade de Gerenciamento de Recurso Hídrico Pontal do Paranapanema

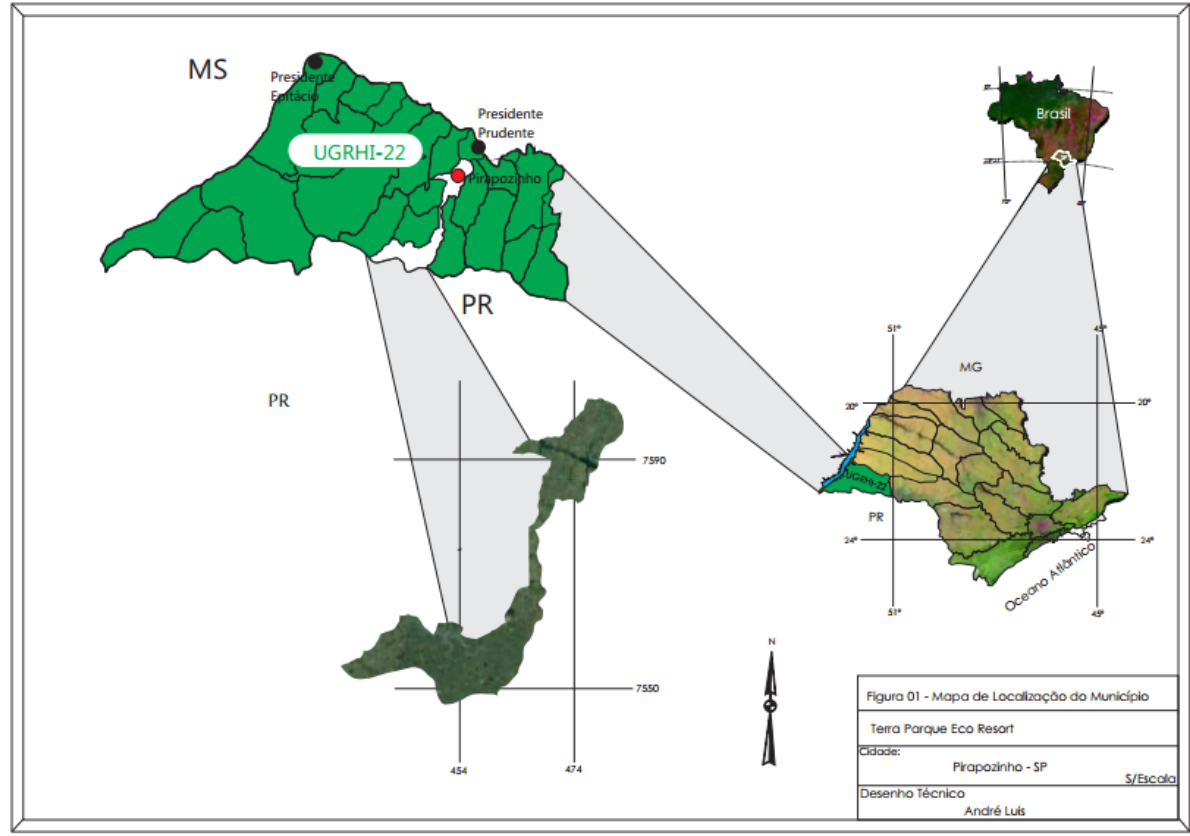

Fonte: O Autor.

O monitoramento (levantamento e amostragem) foi classificado em duas campanhas, realizadas através de análises das fotos da área in loco, observando, sempre, a existência de áreas com restrição legal ao uso (Áreas de Preservação Permanente e Reserva Legal), denominada áreas de refúgio de fauna. A localização, as coordenadas e o tempo de funcionamento das armadilhas fotográficas no local de restrição legal estão descritas no QUADRO 1.

Quadro 1. Localização e tempo de permanência das armadilhas fotográficas

\begin{tabular}{|l|l|l|l|l|}
\hline \multirow{2}{*}{ No da Armadilha Fotográfica } & \multicolumn{2}{|l|}{} & \multicolumn{2}{l|}{ Campanha } \\
\cline { 3 - 6 } & \multicolumn{2}{|l|}{ Coordenadas } & 1a & \multirow{2}{*}{$\mathbf{a}$} \\
\hline & E & $\mathbf{N}$ & & \\
\hline AF-1 & 456.347 & 7.540 .602 & 120 & 120 \\
\hline AF-2 & 456.365 & 7.540 .643 & 118 & 90 \\
\hline AF-3 & 456.420 & 7.540 .734 & 120 & 100 \\
\hline
\end{tabular}

O método de identificação e quantidade dos espécimes encontrados na localidade do presente estudo foi descritos conforme registro (QUADRO 2). Os registros de mamíferos realizados foram diretos: entrevistas com funcionários (adaptadas ao grau de conhecimento frente os espécimes de animais mais evidenciados), armadilhas fotográficas e vestígios da existência de espécies. Sendo este último, a única ferramenta disponível para detectar a presença do exemplar no campo.

Segundo IUCN (2015), existe a importância de entrevista com os trabalhadores presentes nos locais de levantamento de fauna considerando diferentes parâmetros ecológicos, como: grau de tolerância à presença humana; grau de dependência em relação a formações florestais; grau de ameaça de extinção: Decreto Estadual no 60.133/14 e Nacional (IN - MMA 03/03 e Portaria no 444, de 17 de dezembro de 2014).

A dificuldade de estudos de mamíferos silvestres deriva da diversidade de hábitos (diurnos, noturnos ou crepusculares) e habitats (aquáticos, florestais, campestres etc.), da diversidade de espécies e da grande variação de 
tamanho (CULLEN JR, et al., 2006; REIS et al., 2011).

Quadro 2. Identificação dos espécimes quanto sua ordem taxonômica.

\begin{tabular}{|l|l|l|l|}
\hline Classe & Espécie & Nome vulgar & Método de identificação \\
\hline Mammalia & Chrysocyon brachyurus & Lobo-guará & Pegadas \\
\hline Mammalia & Cerdocyon thous & Cachorro do mato & Pegadas \\
\hline Mammalia & Hydrochoerus hydrochaeris & Capivara & Pegadas e fezes \\
\hline Reptília & Salvator merianae & Teiú & Imagem Fotografia - AF 1 \\
\hline Mammalia & Dasypus novemcinctus & Tatu-galinha & Imagem Fotografia - AF 1 \\
\hline Mammalia & Leopardus pardalis & Jaguatirica & Imagem Fotografia - AF 2 \\
\hline Mammalia & Nasua nasua & Quati & Imagem Fotografia - AF 1 \\
\hline
\end{tabular}

Durante a busca ativa as pegadas encontradas foram medidas (FIGURA 2), fotografadas e identificadas, com auxílio de guias de identificação As pegadas fornecem muitas vezes, uma identificação de táxons e áreas de ocorrência.

Figura 2. Método de amostragem de pegada através da busca ativa

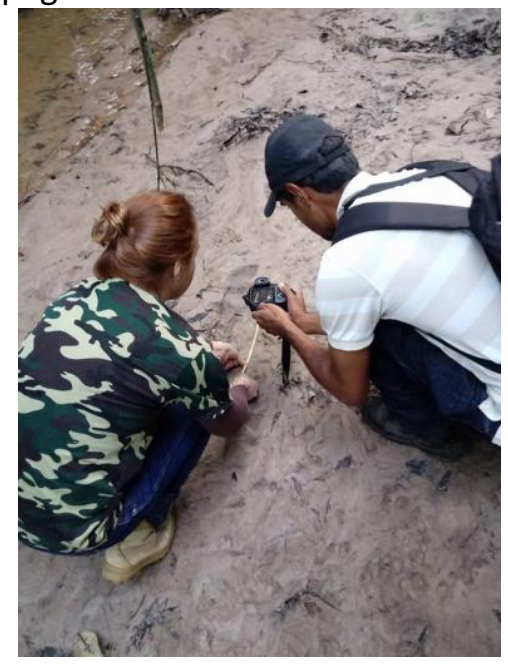

Fonte: O Autor.

Foram identificados animais pertencente ao mesmo grupo como, os carnívoros, pois existem espécies digitígradas como o Cerdocyon thous, cachorros-do-mato e Chrysocyon brachyurus, lobo-guará (FIGURA 3), ambos, registrado através de pegadas as margens do córrego que passa ao fundo do Parque. 
Figura 3. (A) Cerdocyon thous, cachorro-do-mato. Animal não se encontra em nenhuma lista de animais em extinção; (B) Chrysocyon brachyurus, lobo-guara. Está inserido nas listas de ameaças.
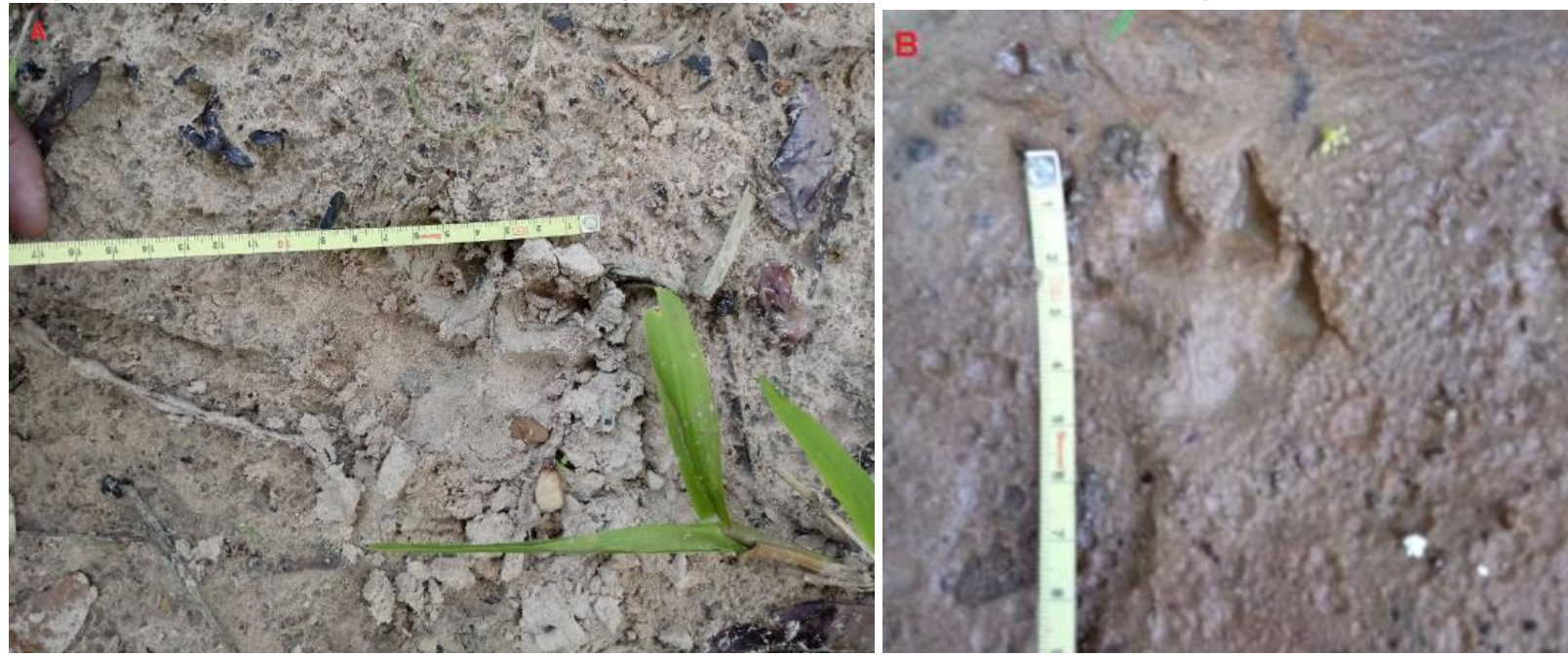

Fonte: O Autor.

Para Ramos (2003), os mamíferos apresentam diferentes formas e tamanhos, e consequentemente, as características básicas de seus rastros também são diferenciadas. Portanto, devem ser analisadas as características como tamanho e forma da almofada plantar e dos dedos, e presença ou ausência de marcas de unhas é essencial para tornar possível a identificação da espécie a qual pertence o rastro.

o Chrysocyon brachyurus, lobo-guara é classificado como ameaçado na lista do Estado de São Paulo, vulnerável (VU) na lista nacional e quase-ameaçado (NT) na lista global. O grau de ameaça da espécie apresentada segue os propostos nas secções da Lista da Fauna Brasileira Ameaçada de Extinção (CHIARELLO et al., 2008).

No presente estudo, a capivara, Hydrochoerus hydrochaeris, foi identificada com pegadas e fezes (FIGURA 4), ambos à margem do córrego, sendo esses vestígios mais facilmente encontrados, sua utilização para identificação dos mamíferos é uma alternativa simples e informativa.

Segundo Herrera (2013), muitos dados podem ser obtidos, pois a ocorrência destes mamíferos está sempre associada a cursos de água como rios e lagos artificiais ou naturais que fornecem proteção, possibilidade de termorregulação e, local propício para a cópula. Possuem áreas de vida que podem ter tamanhos variados conforme a disponibilidade de recursos e o tamanho do grupo, mas que raramente ultrapassam $500 \mathrm{~m}$ de distância dos corpos d'água. 
Figura 4. (A) Pegada de capivara, Hydrochoerus hydrochaeris; (B) Fezes.
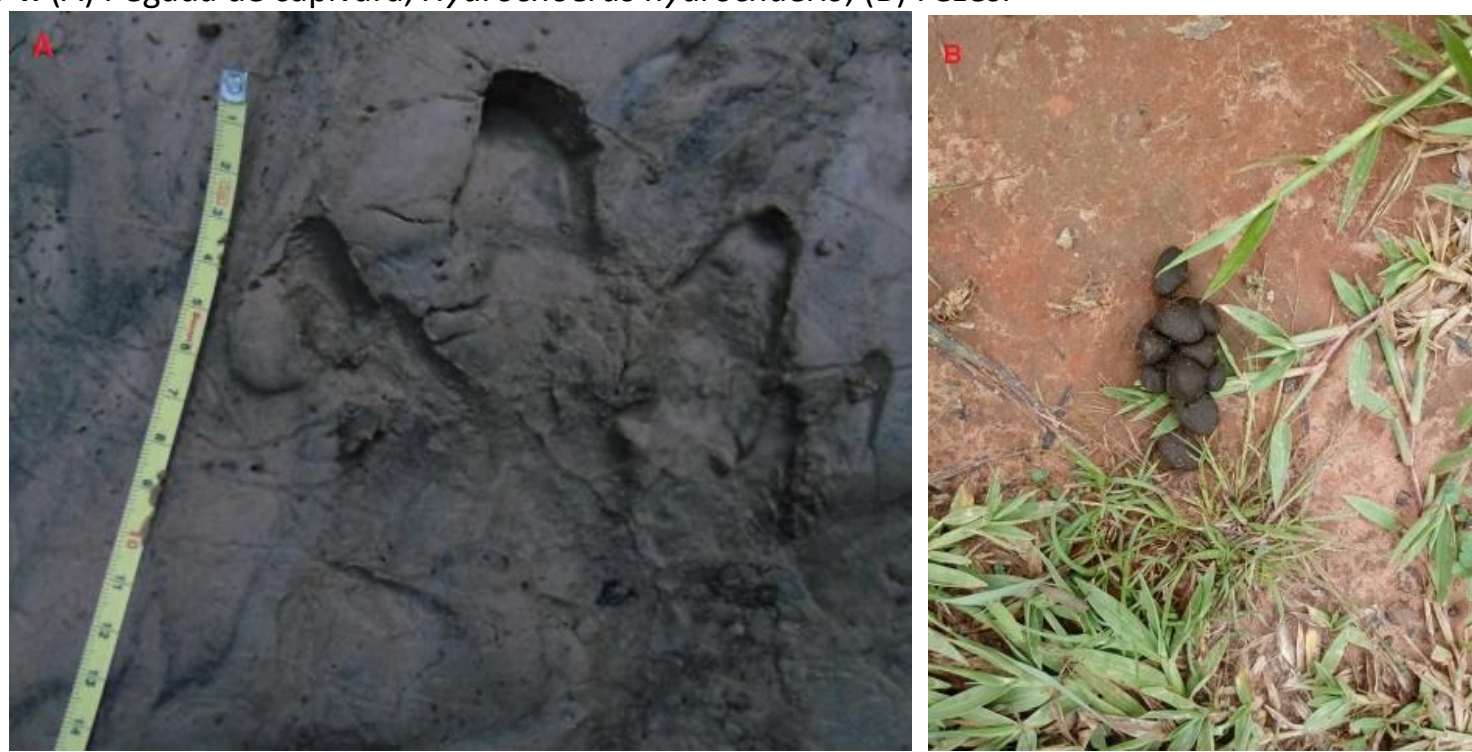

Fonte: O Autor.

As armadilhas fotográficas são câmeras automáticas de métodos não invasivo e eficiente, acionadas por um sensor de movimento.

No presente estudo (FIGURA 5), consististe na montagem das câmeras em pontos estratégicos com as coordenadas supracitadas.

Figura 5. (A) Montagem da câmera "trap"; (B) Sensor de movimento da câmera.
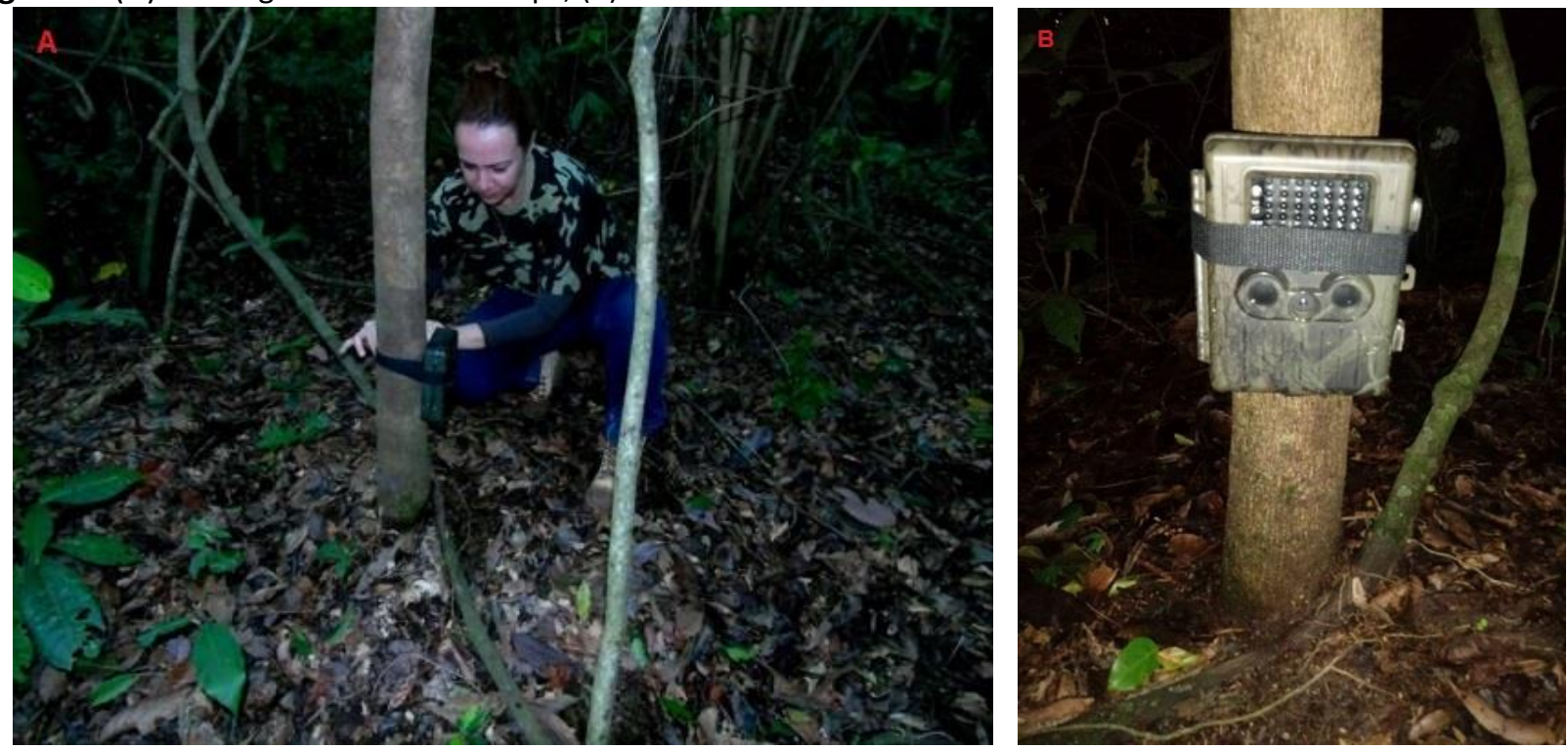

Fonte: O Autor.

As armadilhas inseridas estrategicamente em áreas com indícios de ocorrência registraram imagens dos espécimes como: Dasypus novemcinctus, tatu-galinha (FIGURA 6);
Leopardus pardalis, jaguatirica (FIGURA 7); Nasua nasua, quati (FIGURA 8). 
Figura 6. Imagem de tatu-galinha.

Fonte: O Autor.

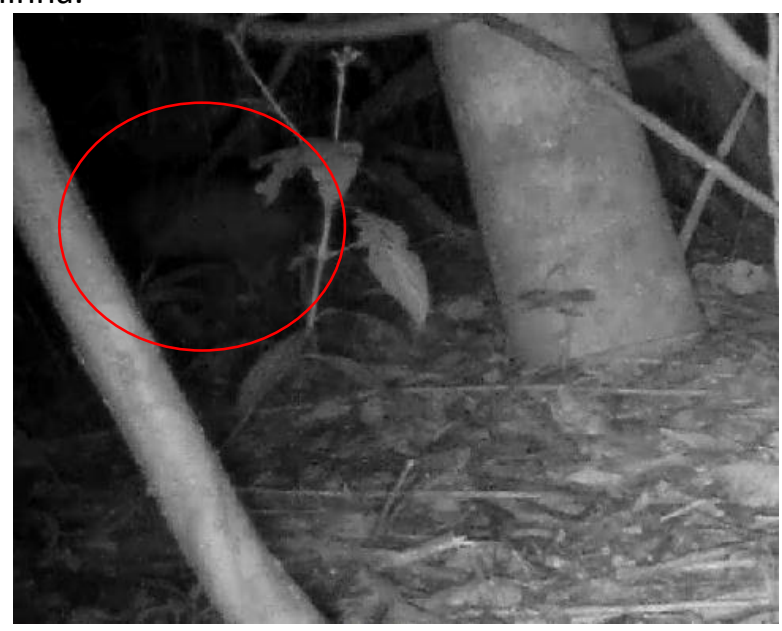

Os tatus possuem grande expressão nos biomas brasileiros. Principalmente o tatu galinha (Dasypus novemcinctus) é mais comum devido a sua ampla distribuição geográfica (CULLEN JR, et al., 2006).

Figura 7. Imagem fotográfica - L. pardalis.

\section{$20: 57: 45$}

Fonte: O Autor.

A jaguatirica (Leopardus pardalis) é, dentre os pequenos gatos pintados do gênero Leopardus, a maior espécie. No Brasil ocorre em todos os estados com exceção provável do Rio Grande do Sul, ocupando as diferentes fitofisionomias do cerrado, caatinga, pantanal e principalmente as florestas tropicais e subtropicais (CUBAS et al., 2014). Para Oliveira (2005), apesar da variabilidade de ambientes onde a jaguatirica pode ocorrer, ela não é considerada uma espécie generalista de habitat.

É classificada como ameaçadas na lista do Estado de São Paulo, tendo sido considerada como vulneráveis (VU) na lista nacional, propostos nas secções da Lista da Fauna Brasileira Ameaçada de Extinção (CHIARELLO, 2008). 
Figura 8. Captura de imagem fotográfica por câmera "trap" de N. nasua.

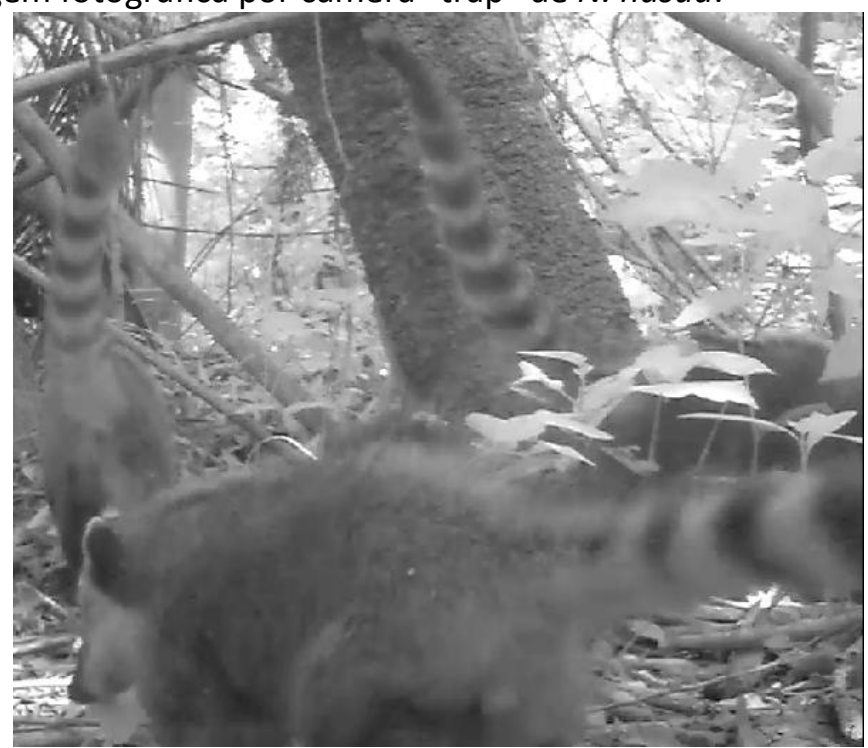

Fonte: O Autor.

N. nasua, quati, é classificada como a décima quinta espécie de mamífero mais abundante em florestas neotropicais, sendo enquadrada na categoria "de ampla distribuição geográfica e alta densidade" (CUBAS et al., 2014).

Em contrapartida, répteis são animais inconspícuos e de difícil amostragem, sendo muitas vezes complexo avaliar. No presente estudo, foi registrado um exemplar de Salvator merianae, vulgarmente conhecido com teiú, foi capturado pela câmera "trap" AF 1 (FIGURA 9).

Figura 9. Captura de imagem fotográfica por câmera "trap" de Salvator merianae.

Fonte: O Autor.

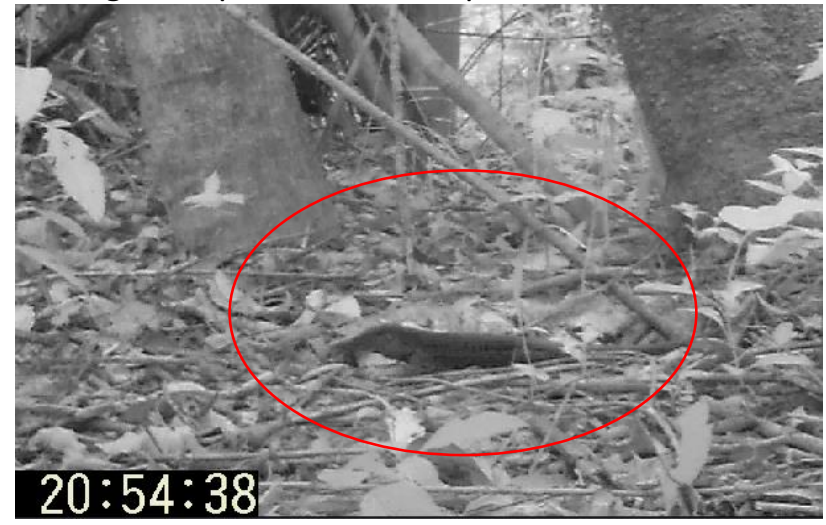

É uma espécie que ocorre desde o sul do Amazonas ao norte da Argentina. Seu hábitat inclui florestas, cerrados e caatingas. O teiú, poderá tornar-se ameaçado de extinção devido ao tráfico e a caça (CULLEN JR, et al., 2006).

\section{Conclusão}

Conclui-se que boas práticas do monitoramento com armadilha fotográfica, visualização direta e por vestígios para o levantamento de fauna silvestre observada na estação da primavera durante as duas companhas foram de grande valia para a identificação dos espécimes maximizar os esforços de conservação a nível local, tratando-se de um estabelecimento turístico. Levando-se em consideração a estação do ano como fator reprodutivo e época onde há maior oferta e distribuição de alimentos.

\section{Agradecimento}

$\mathrm{O}$ autor gostaria de agradecer a Garden Ecotur de Presidente Prudente/SP por colaborar com a realização do estudo referente ao empréstimo dos equipamentos e apoio prestado. 


\section{Referências}

BRANDON, K.; FONSECA, G.A.B.; RYLANDS, A.B.; SILVA, J.M.C. Conservação Brasileira: desafios e oportunidades. Megadiversidade, v. 1, p. 7-13, 2005.

BRASIL. Ministério do Meio Ambiente. Listas Nacionais de espécies ameaçadas de extinção Fauna. Brasília: Ministério do Meio Ambiente, 2014.

CHIARELLO, A.G.; AGUIAR, L.M.S.; CERQUEIRA, R.; MELO, F.R.; RODRIGUES, F.H.G.; SILVA, V.M.F. Mamíferos ameaçados de extinção no Brasil. In: MACHADO, A.B.M.; DRUMMOND, G.M.; PAGLIA, A.P. (eds.). Livro vermelho da fauna brasileira ameaçada de extinção. Brasília: Ministério do Meio Ambiente, Fundação Biodiversitas, 2008. 1420p. vol. 2.

CUBAS, Z.S.; SILVA, J.C.R.; CATÃO-DIAS, J.L. Tratado de animais selvagens: medicina veterinária. 2. ed. São Paulo: Roca, 2014.

CULLEN JR, L.; RUDRAN, R.; VALLADARES-PADUA, C. Métodos de estudos em biologia da conservação \& manejo da vida silvestre. 2. ed. Curitiba: Editora UFPR, 2006.

CPTI. Diagnóstico da situação dos recursos hídricos da UGRHI - 22. Pontal do Paranapanema: Relatório Zero. São Paulo: CPTI, 1999. CD-ROM.

DIRZO, R.; YOUNG, H.S.; GALETTI, M.; CEBALLOS, G; ISAAC, N.J.B.; COLLEN, B. Defaunation in the anthropocene. Science, v. 345, p. 401-406, 2014. https://doi.org/10.1126/science.1251817

GREEN, J.J.; BRADSSHAW, C.J.A. The "capacity to reason" in conservation biology and policy. Journal for Nature Conservation, v. 12, p. 25-39, 2004. https://doi.org/10.1016/i.jnc.2004.04.001

HERRERA, E.A. Capybara Social Behavior and Use of Space: Patterns and Processes. In: MOREIRA, J.R.; FERRAZ, K.M.P.M.B.; HERRERA, E.A.; MACDONALD, D.W. eds. Capybara: Biology, Use and Conservation of an Exceptional Neotropical Species. New York: Springer Science Business Media. p.195-207, 2013. https://doi.org/10.1007/978-1-4614-4000-0 11
IUCN. The IUCN Red List of Threatened Species, 2015. Disponível em: <http://www.iucnredlist.org.>. Acesso em: 29 jan. 2019.

LEAL, R.P. Considerações sobre manejo de fauna. In: BAGER, A., org. In: SIMPÓSIO DE ÁREAS PROTEGIDAS - PESQUISA E DESENVOLVIMENTO SÓCIO-ECONÔMICO, 1. Anais [...]. Pelotas, 2-4 de outubro de 2001. Pelotas: Educat.

LEITE, J.F. A ocupação do Pontal do Paranapanema. São Paulo: Hucitec, 1998.

O'CONNELL, A.; NICHOLS, J.; KARANTH, U. Camera traps is animal ecology: methods and analyses. 1. ed. Tokyo: Springer, 2011. 271p. https://doi.org/10.1007/978-4-431-99495-4

OLIVEIRA, T.G.; CASSARO, K. Guia de campo dos felinos do Brasil. Instituto Pró-Carnívoros, 2005. $80 p$.

POTTS, S.G.; BIESMEIJER, J.C.; KREMEN, C.; NEUMANN, P.; SCHWEIGER, O.; KUNIN, W.E. Global pollinator declines: trends, impacts and drivers. Cell Press, v. 25, n. 6, p. 345-353, 2010. https://doi.org/10.1016/j.tree.2010.01.007

RAMOS, V. A.; PESSUTI, C.; CHIRENGATTO, C. A. F. S. Guia de Identificação dos Canídeos Silvestres Brasileiros. Sorocaba, Joy Joy Studio, Comunicação Ambiental, 2003. 34p.

REIS, N.R.; PETACCHI, A.L.; PEDRO, W.A.; LIMA, I.P. Mamíferos do Brasil. Londrina: Universidade Estadual de Londrina, 2011. 439p.

SHAH, A. Climate change affects biodiversity. 2012. Disponível em: http://www.globalissues.org/article/172/climatechange-affects-biodiversity. Acesso em: 27 jun. 2017. 